\title{
THE UNIVERSITY OF IOWA
}

TO:

Director, National Institute for Occupational Safety and Health

FROM:

lowa FACE

Case no. 2011 IA 075

Report date: 18 September 2012

SUBJECT: Truck driver died of thermal injuries after his tractor-trailer crashed into concrete median on the interstate and burst into flames

\section{SUMMARY}

A 40-year-old long-distance truck driver died in 2011 from thermal injuries after his tractor-trailer struck a concrete barrier median on an interstate highway. The driver was the single occupant of a fully loaded tractor-trailer travelling east at highway speed on a six-lane section of interstate. The truck tractor struck the concrete median in an abrupt steering movement toward the left, and then moved along the concrete median, damaging the drivers-side fuel tank and generating friction and heat, which ignited diesel fuel in the tank. The driver steered to bring the vehicle away from the median and the trailer jackknifed, striking the median with a force that broke sections of median barriers and knocked the rear dual axles off the trailer. The box of the trailer then rode up on top of the median and continued to ride on top of the median as the vehicle moved east. The vehicle came to rest when the trailer flipped onto its left side. The center of the trailer was on top of the median, and the rear of the trailer was on the north side of the median in the inside shoulder of west-bound lanes. The tipping of the trailer twisted the tractor, causing the tractor to rest against the center median with the passenger side elevated. The tractor cab and engine were engulfed in flames. Firefighters responded and extinguished the fire and then located the driver's body outside the cab. The cause of the crash was not determined, but fatigue or distracted driving may be plausible causes. The driver had concluded a cell phone conversation 10 miles west of the crash site. Shortly after this and other similar crashes involving semi-truck drivers, legislation was passed by the Federal Motor Carrier Safety Administration (FMCSA) banning handheld cell phone use while driving a truck involved in interstate commerce.

\section{RECOMMENDATIONS}

1. Truck drivers should be trained to recognize signs of fatigue.

2. Drivers of commercial motor vehicles should avoid distracted driving to prevent driver errors and subsequent collisions. 
3. Design and selection of truck tractors should incorporate risk of fuel tank location.

4. Maintain a space cushion around the truck to avoid driving too close to stationary objects and other vehicles.

\section{INTRODUCTION}

A truck driver was killed after his tractor-trailer struck the concrete median barrier on an interstate highway and caught fire. The lowa FACE program learned of the fatality through news media the evening of the event. Iowa FACE conducted interviews with the Chief of the responding fire department and the investigating lowa State Patrol officer, both of whom were present at the scene and filed incident reports. This case investigation was prepared using information from the lowa State Patrol/lowa Department of Transportation Investigating Officer's Report of Motor Vehicle Accident, incident reports filed by the responding fire department, the lowa State Medical Examiner's preliminary report, and final autopsy prepared by the pathology department of the local hospital. Iowa FACE contacted the driver's employer, but the employer declined to provide information on this case.

\section{INVESTIGATION}

The victim was a 40-year-old long-distance hauler employed by a Midwest freight transportation company. No information was available from the employer regarding the truck driver's employment history or driving log record.

At the time of this incident, the driver was driving a fullyloaded 80,000-pound (gross combined weight), 2007 International 9400 l tractor pulling a 1999 Wabash semitrailer. Earlier in the day, he picked up a load of canned pet food in Nebraska and drove approximately 225 miles before stopping to refuel. He continued travelling approximately 115 miles east on the route to his Indiana delivery site. The estimated driving time on this delivery, prior to the accident, was $5 \frac{1}{2}$ hours, excluding refueling or other stops the driver made along the way.

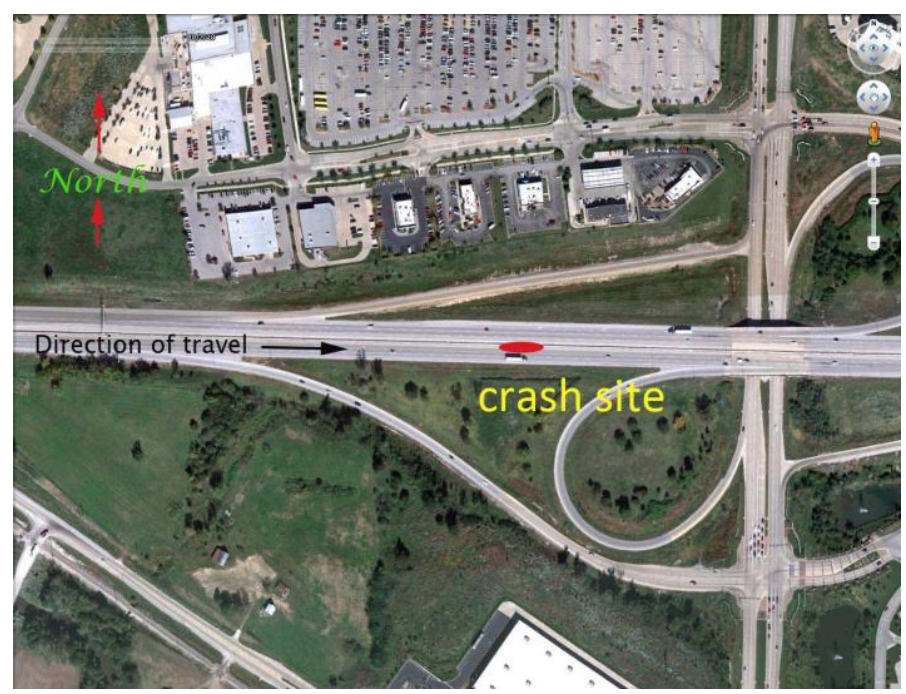

Exhibit 1. Location of crash site
Comment [sal1]: We are waiting for: 1) mike hicks ISP to give account of what hit what, first (tractor vs trailer)

3) guy sommers $\mathrm{ME}$ - confirmation that guy got of phonew/wife@ specific location near

oxford/tiffin area (10 miles prior to crash) mobile or at rest stop? 
The driver was travelling east on a section of interstate highway that had three east-bound and three west-bound lanes (Exhibits 1 and 3 ) separated by a center median of concrete F-shape barriers ${ }^{1}$ pinned end to end (Exhibit 2). The posted speed limit was $65 \mathrm{mph}$. There was no road construction activity on this stretch of highway.

The evening of the crash, the weather was clear, with 65 ${ }^{\circ} \mathrm{F}$ temperature and light winds from the SSE between 5 and 8 miles per hour (mph). The light conditions were dark, as civil twilight occurred at 1829 , an hour prior to the crash.

The driver concluded a cell phone conversation with a family member at a location approximately 10

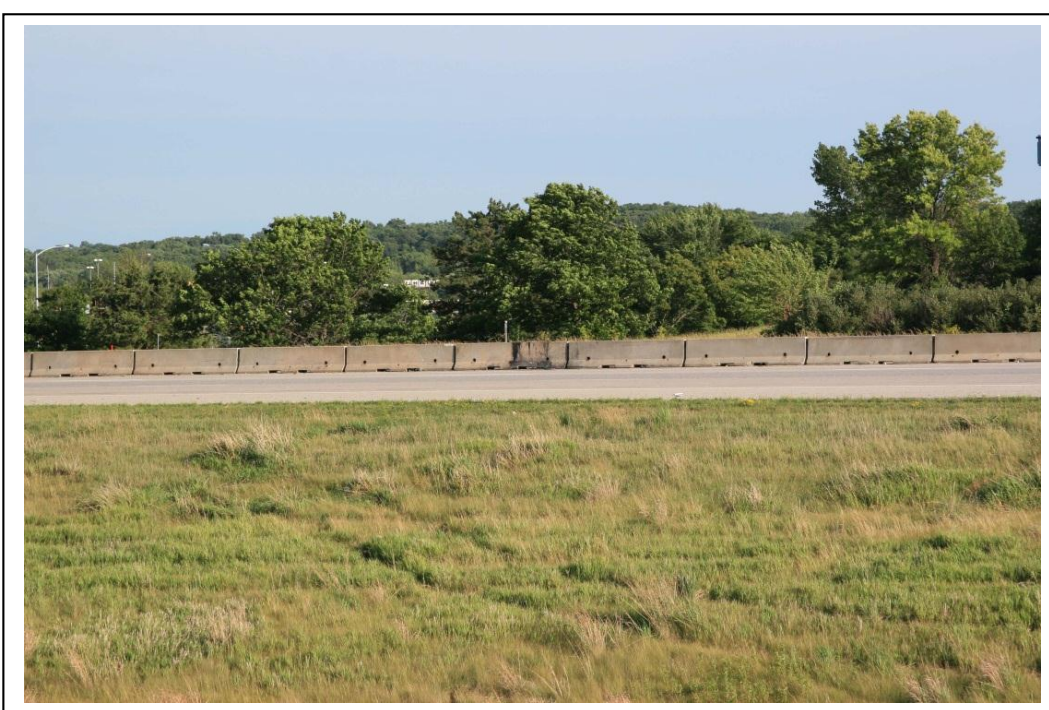

Exhibit 2. Concrete median of F-shape barriers at site

miles west of the crash site (an estimated 7-10 minutes before to the crash).

The accident occurred as the driver was travelling in the left lane, next to the median, approximately 1.5 miles east of a major highway interchange. A wide left shoulder lane, nearly the width of a driving lane, was between the left travel lane and the concrete-barrier median at this location.

The lowa State Patrol indicated that the driver was travelling at $62 \mathrm{mph}$, and then veered left, striking the concrete median with the left side of the tractor. The vehicle continued east on the left shoulder with the driver's side of the tractor scraping against the median. The driver steered right to correct his position. Attempts to realign the vehicle caused the trailer to jackknife and orient approximately 30 degrees off of the road centerline. As the driver tried to re-center the vehicle on the freeway, the rear of the jackknifed trailer struck the concrete barrier with a force that broke the barriers, broke the rear double axles from the trailer, and drove the rear of the trailer up over the median, where it rode atop of the median before the vehicle came to rest (Exhibit 3).

\footnotetext{
1 http://en.wikipedia.org/wiki/F-Shape barrier lowa DOT Section 2513. Concrete Barrier Specification: http://www.iowadot.gov/erl/current/GS/content/2513.pdf lowa DOT Standard Road Plan BA-100 http://www.iowadot.gov/design/SRP/IndividualStandards/eba100.pdf 2011 IA 075

18 September 2012

Page 3 of 10
} 
When the driver's side of the tractor hit and scraped against the concrete median, the diesel fuel saddle tank (located below the cab door on the driver's side of the cab) came into contact with the concrete median barriers. Friction between this aluminum fuel tank and the concrete barriers damaged the tank and generated heat and sparks. This heat atomized the diesel fuel, and sparks

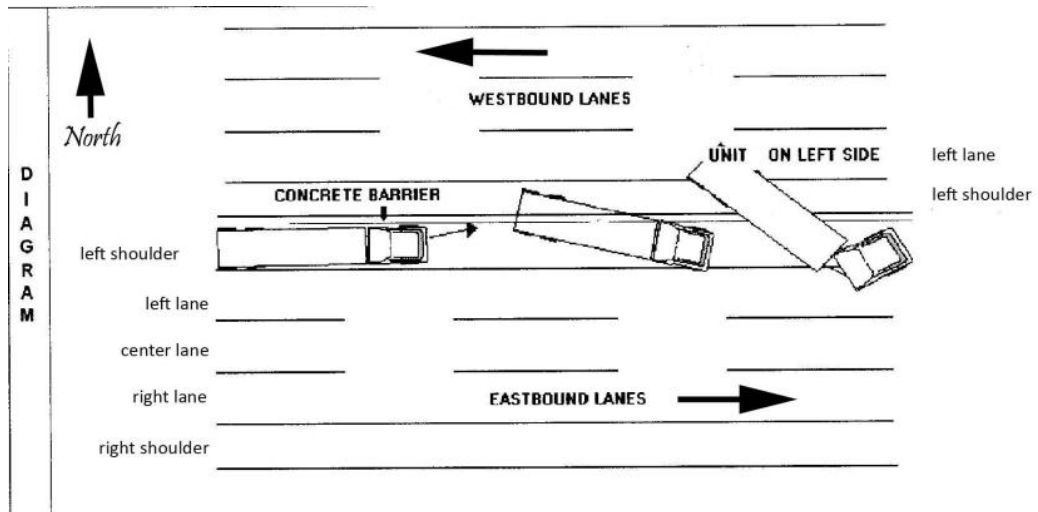

Exhibit 3. Path of vehicle as shown on motor vehicle incident report ignited the atomized fuel, causing the tractor to catch fire.

The vehicle came to rest with the trailer attached and flipped onto its left side, atop the median. The rear of the trailer was extended into the westbound left shoulder and left traffic lane. Tipping of the trailer caused the tractor to twist into a position with the driver's side in contact with the concrete median, and the passenger side of the tractor elevated. The tractor cab and engine were completely engulfed in flames (Exhibit 4).

The local fire department, responding from 2 stations within 2.5 miles of the fire scene, received a 911 call at 1942 and arrived at the scene at 1956. The lowa State Patrol, city police, and a neighboring fire department also responded to assist with traffic control.

Fifteen local fire fighters arrived to find the cab of the tractor fully involved in fire. Fuel was running down the interstate and burning. One unit began an attack at the truck cab and the other unit began an attack at the rear of the trailer. The fire was extinguished approximately one hour after firefighters began fire suppression.

After the fire was extinguished, firefighters searched for the driver, whose body was found in a supine position outside and to the rear of the cab, between the tractor and the median. The driver's location and position suggested he left the cab or fell through the driver's door and was engulfed in the fire. The location of cargo contents near the cab suggested that some of the contents spilled from the burning trailer after the driver had fallen to the ground. The driver suffered extensive burn injuries. 


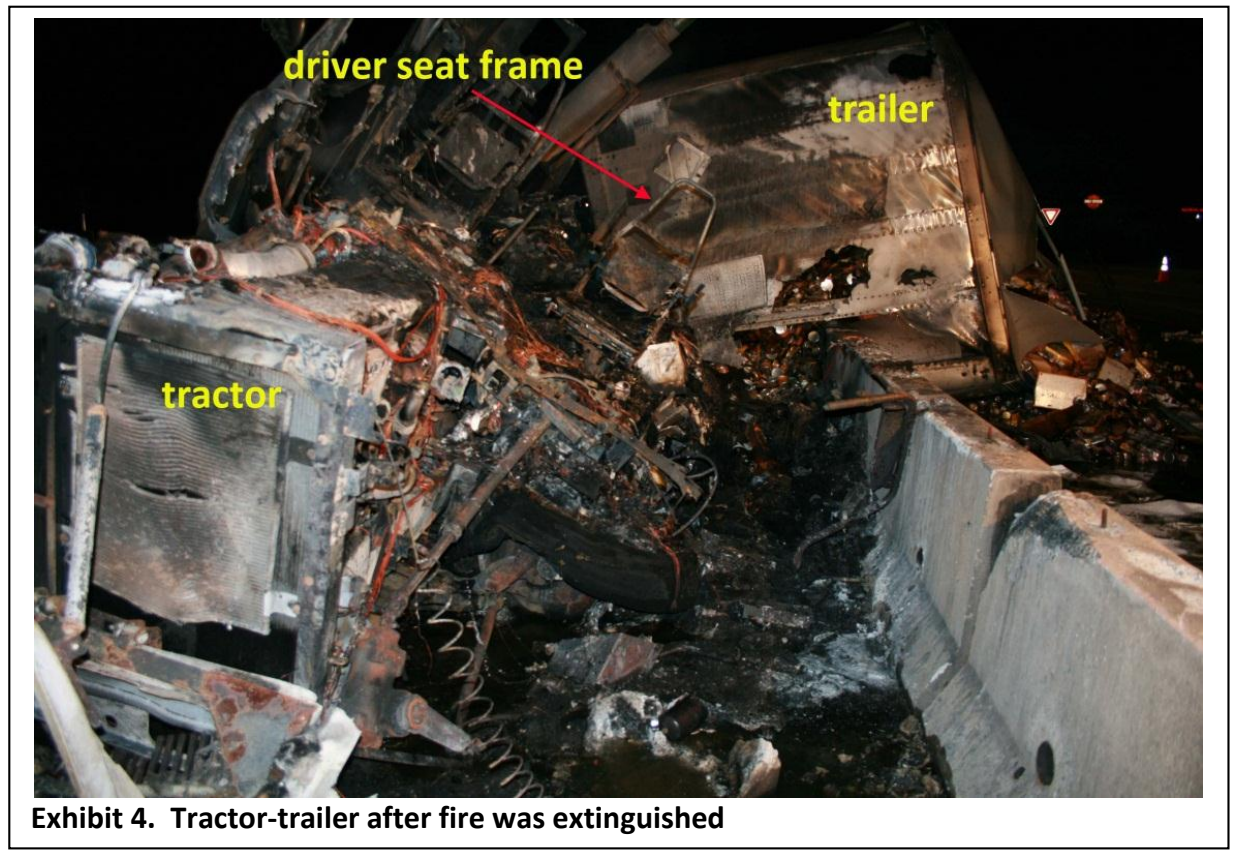

The lowa State Patrol investigation noted there were no known conditions contributing to this crash related to weather, road surface, roadway junction, or environment. Contributing circumstances related to the driver were noted as 'unknown'. There remained no evidence in the burned cab to ascertain potential distractions that could have contributed to his initial veering in the left lane. There were no reports from witnesses of contributing factors - such as objects or animals in the road, other vehicle actions, or traffic from the on-ramp downstream (west) of the crash site - that may have caused the initial swerve preceding the crash. The drivers' speed was within the posted speed limit.

The driver's daily log was not unrecoverable from the fire, and the driver's employer declined to provide this information.

\section{CAUSE OF DEATH}

The final autopsy reported the driver's cause of death as thermal and inhalation injuries. The autopsy noted extensive thermal injuries of most body surfaces; evidence of inhalation of products of combustion characterized by soot material lining the upper and lower airways; accumulation of fluid in the lungs and airways; and elevated carboxyhemoglobin saturation of the blood (27.6\%). Autopsy findings indicated the driver was alive for a short period of time after initiation of the fire. There were no medical conditions that contributed to the crash or fatality. 


\section{RECOMMENDATIONS AND DISCUSSION}

\section{Recommendation 1: Truck drivers should be trained to recognize signs of fatigue.}

The driver's known route from pick-up of his load in Nebraska to the site of the crash involved an estimated 5.5 hours of driving prior to the crash. While it is unclear whether the driver had been driving during the 5 hours before picking up this load (i.e., within the allotted 11-hour allowable driving shift period), the driver's initial swerve left may be indicative of fatigued driving. Recommendations to fight fatigue include requiring drivers to stop en route every 100 miles or 2 hours, or to change routes to prevent driving from becoming routine. Additional specific recommendations to fight fatigue when driving are addressed by the DOTs Federal Motor Carrier Safety Administration (FMCSA 2009) document.

\section{Recommendation 2: Drivers of commercial motor vehicles should avoid distracted driving to prevent driver errors and subsequent collisions.}

Because no evidence or witnesses indicated traffic-related sources for the initial swerving of the tractor-trailer (e.g., no tire failure, no erratic or sudden lane changes by other-vehicles) and no medical conditions were attributed causes for the driver's initial lane departure, a second plausible cause for this crash is distracted driving.

About $12 \%$ of crashes $(n=4,808)$ on the US public roads in 2007 involved large trucks. In a naturalistic driving study conducted by the Department of Transportation, it was found that $82 \%$ of crashes, near-crashes, crash-relevant conflicts and unintentional lane deviations are due to driver distraction (FMCSA, 2009). Seemingly slight distractions - such as reaching for or dropping an object, or putting an object away - and more involved distractions - such as cell phone or on-board computer use, eating or drinking, reading road maps or directions, smoking, changing music settings, or even addressing pets in a vehicle - could lead to lethal driving errors. In this case, the driver's sudden swerve to the left may have resulted from reaching to the right: leaning or reaching toward the right results in a pull of the steering wheel toward the left.

The investigating lowa State Patrol officer indicated that the driver ended a cell phone call at a location approximately 10 miles west of the crash (i.e., a period of 7-10 minutes prior to the crash). Although the root cause of this driver's crash was not known, it is possible that cell phone use may have contributed to distraction leading to this crash. The National Safety Council addressed distraction involving hands-free phones in a 2010 white paper, noting that while hands-free devices eliminate two risks - visual (looking away from the road to operate a hand-operated cell phone) and manual (removing hands from the steering wheel) - hands-free devices do not eliminate cognitive distraction. Long telephone conversations and the time spent after conversations, while drivers are mentally reviewing and processing and those conversations, are times in which drivers are cognitively distracted and less alert to vehicle, road, and environmental conditions. A driver's responses to sudden hazards are compromised when the brain must switch attention and focus from one task (processing telephone conversation) to another (responding to a sudden hazard like objects in the road, or another driver's maneuvers, etc.). 
This particular case and a flurry of recent tragic crashes involving distracted cell phone use among commercial vehicle drivers led to the passage of a new policy passed by the FMCSA that prohibits commercial drivers from using handheld mobile telephones while operating a commercial truck or bus. In addition, motor carrier companies are prohibited from requiring or allowing commercial drivers to use handheld mobile devices. Penalties for drivers violating this policy include fines up to $\$ 2,750$, and disqualification for multiple offenses. Companies who violate this policy may be subject to penalties up to $\$ 11,000$.

\section{Recommendation 3: Design and selection of truck tractors should incorporate risk of fuel tank location.}

A recent study of Kentucky motor vehicle crashes involving fires showed that large trucks were at higher risk for collisions involving fire than passenger vehicles and light trucks (Bunn, 2012). Factors influencing fire risk include truck size (i.e., greater impact force at crash); large fuel capacity; and fuel tank placement.

The truck involved in this event (2007 International Tractor 9400I) had two diesel fuel saddle tanks of at least 100 gallon capacity each, affixed to the tractor directly behind the front axle, outside the tractor frame, and beneath the driver and passenger cab doors (Exhibit 5). Two steps were permanently

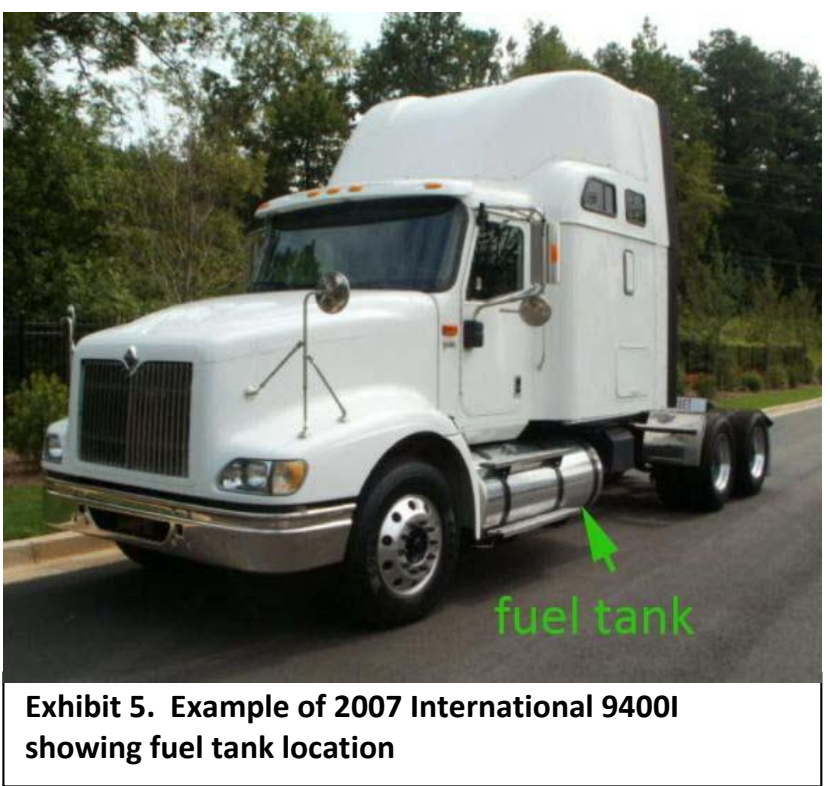
mounted over each tank to allow a driver and passenger to enter and exit the cab. The aluminum fuel tanks are exposed, extending beyond the profile of the tractor cab and outside of the trailer's structural frame. These tanks are positioned at a height below the top of the 44-inch-high F-shape concrete barrier median; in the event the side of the truck contacts a concrete median or shoulder barrier, the fuel tank is likely to be damaged. At freeway speeds, a tractor that contacts the barrier will generate friction and heat at the exterior surface of the fuel tank, increasing the likelihood of tank failure and fire upon impact or contact.

The driver had limited escape options in this incident (since the passenger side of the truck was elevated from the crash, and opened into the main path of oncoming interstate traffic), and his exit out the driver's side door was the quickest and most logical escape plan. However, this exit required him to step or jump over the fuel tank that had been in contact with the concrete median. The position of the fuel tank under the driver's door required him to travel through the fire to escape the vehicle. If the tanks were positioned further under the cab, or if they had protective framing between the fuel tank

2011 IA 075

18 September 2012

Page 7 of 10 
and concrete median, the driver's side tank may have survived the damage and/or the driver may have had additional protection and time to escape.

\section{Recommendation 4: Maintain a space cushion around the truck to avoid driving too close to stationary objects and other vehicles.}

Safe driving is critical to reduce crashes and crash-related fatalities, particularly for oversized vehicles that require more skill to negotiate highways and roads with roadway structures and other vehicles. Drivers of oversized vehicles are recommended to maintain a space cushion (Exhibit 6), which is defined as the area that surrounds the vehicle on all sides, especially the tractor sides where fuel tanks reside. In the case of this fatality, the space between the driver side and the concrete barrier was not maintained as the vehicle first swerved toward the left and then

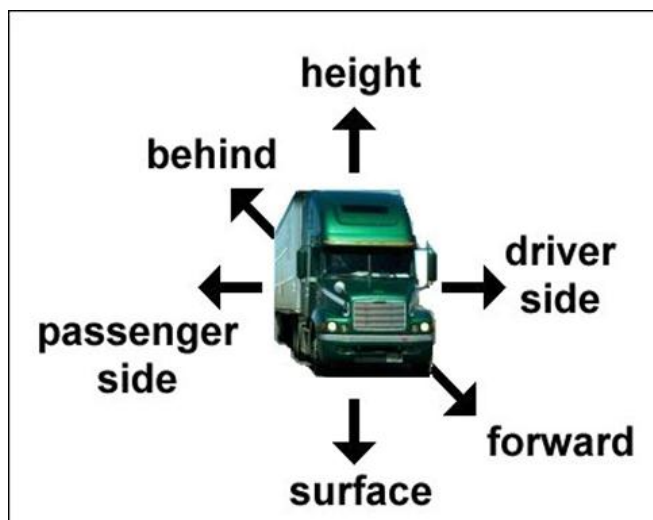

Exhibit 6: Depiction of space cushion for large trucks (http://www.truck-drivers-moneysaving-tips.com/safe-driving.html) scraped beside and over the top of the median.

At the time of this report, the FMCSA is in the midst of testing the effectiveness of on-board monitoring systems in improving safety. Forward Collision Warning Systems (CWS) are in-vehicle electronic systems with capability to monitor the roadway ahead of the vehicle, and warn the driver of potential collision risks. Lane Departure Warning Systems (LDWS) are in-vehicle electronic systems that monitor the position of the vehicle in the roadway lane, and alert the driver of lane departure when travelling above a speed threshold, without use of the vehicle's turn signal. Both CWS and LDWS have capability to store data that can be retrieved by fleet managers to evaluate driving patterns, and train drivers regarding

risky behaviors. Results of the FMCSA's evaluation of these and other on-board monitoring systems are expected in 2013.

lowa FACE thanks the lowa State Patrol and responding Fire Chief for assistance in developing this case study.

Keywords: $\quad$ truck driver, tractor trailer, fire, highway accident, vehicle struck barrier 


\section{References}

Federal Motor Carrier Safety Administration (FMCSA), US Department of Transportation (US DOT). 2009. Driver distraction in commercial vehicle operations. Washington, DC. http://www.distraction.gov/research/PDF-Files/Driver-Distraction-Commercial-VehicleOperations.pdf.

FMCSA, US DOT. 2007. Large truck crash overview. Washington, DC. http://ai.fmcsa.dot.gov/CarrierResearchResults/PDFs/2007LargeTruckCrashOverview.pdf.

FMCSA, US DOT. 2012. Mobile Phone Restrictions Fact Sheet. Washington, DC. http://www.fmcsa.dot.gov/documents/rulesregs/distracted-driving/MobilePhoneRule-FactSheet.pdf.

National Safety Council (NSC). 2010. Understanding the distracted brain; why driving while using hands-free cell phones is risky behavior.

http://www.fnal.gov/pub/traffic safety/files/NSC\%20White\%20Paper\%20-

\%20Distracted\%20Driving\%203-10.pdf.

Truck-Drivers-Money-Saving-Trips.com. Safe driving tips for drivers of large trucks. http://www.truck-drivers-money-saving-tips.com/safe-driving.html.

Federal Highway Administration, US DOT. McDevitt, C. 2000. Basics of concrete barriers. Public Roads, 63(5).

http://www.fhwa.dot.gov/publications/publicroads/00marapr/concrete.cfm.

Bunn TL, Slavova S, Robertson M. 2012. Crash and burn? Vehicle, collision, and driver factors that influence motor vehicle collision fires. Accident Analysis \& Prevention, 47:140-145.

http://dx.doi.org/10.1016/i.aap.2011.10.008.

FMCSA, US DOT. 2009. A Motor Carrier's Guide to Improving Highway Safety: Evaluation and Technical Assistance Program (FMCSA-ESO-08-003).

http://www.fmcsa.dot.gov/safety-security/eta/ETA\%20Final\%20508c.pdf.

VFIS RISK COMMUNIQUÉ. 2012. Driver Monitoring Systems.

http://www.vfis.com/documents/DriverMonitoringSystems.pdf.

FMCSA, US DOT. 2005. Concept of Operations and Voluntary Operational Requirements for Forward Collision Warning Systems (CWS) and Adaptive Cruise Control (ACC) Systems On-board Commercial Motor Vehicles. http://www.fmcsa.dot.gov/facts-research/research-technology/report/forwardcollision-warning-systems.htm.

FMCSA, US DOT. 2005. Concept of Operations and Voluntary Operational Requirements for Lane Departure Warning Systems (LDWS) On-board Commercial Motor Vehicles. http://www.fmcsa.dot.gov/facts-research/research-technology/report/lane-departure-warningsystems.htm.

2011 IA 075

18 September 2012

Page 9 of 10 
Report Prepared by:

Marizen Ramirez, MPH, PhD

Program Director

T. Renee Anthony, PhD, ClH, CSP

FACE Investigator

Stephanie Leonard, MS

FACE Investigator

2011 IA 075

18 September 2012

Page 10 of 10 


\section{Fatality Assessment and Control Evaluation \\ FACE}

Fatality Assessment and Control Evaluation (FACE) is a program of the National Institute for Occupational Safety and Health (NIOSH), which is part of the Centers for Disease Control and Prevention of the US Department of Health and Human Services. Nationally, the FACE program identifies traumatic work-related deaths, conducts in-depth studies of select cases, makes recommendations for prevention, and publishes reports and alerts. The goal is to prevent occupational fatalities across the nation.

The NIOSH head office in Morgantown, West Virginia, carries out an intramural FACE case surveillance and evaluation program and also funds state-based programs in several cooperating states. The lowa FACE program is conducted by the Injury Prevention Research Center at the University of lowa working in conjunction with the lowa Department of Public Health and its Office of the State Medical Examiner.

NIOSH combines its and the state programs' information for wide dissemination, in a variety of forms, among the industries involved. NIOSH publications are available on the web at http://www.cdc.gov/NIOSH/FACE/ and from the NIOSH Distribution Center (1-800-35NIOSH).

Iowa FACE also publishes its case studies, issues precautionary messages, and prepares articles for trade and professional publications. In addition to postings on the national NIOSH website, the information is posted on the lowa FACE website (www.public-health.uiowa.edu/FACE/).

The lowa FACE team at the University of lowa includes Marizen Ramirez, Director; Corinne PeekAsa, Co-Investigator; John Lundell, Co-Investigator; T. Renée Anthony, Co-Investigator; and Stephanie Leonard, Field Investigator. Additional expertise is provided from the lowa Department of Public Health, including Rita Gergely, Principal Investigator; Kathy Leinenkugel, Surveillance Specialist; and John Kraemer, Director, Forensic Operations at lowa Office of the State Medical Examiner.

\begin{tabular}{|c|}
\hline For additional information regarding this report or the lowa FACE Program contact: \\
lowa FACE \\
The University of lowa \\
Department of Occupational and Environmental Health \\
UI Research Park, 240 IREH \\
lowa City, IA 52242-5000 \\
Toll free: (800) 513-0998 \\
Fax: (319) 335-4085 \\
Internet: http://www.public-health.uiowa.edu/FACE \\
E-mail: stephanie-leonard@uiowa.edu
\end{tabular}

